\title{
Microanalysis of Copper-Tin Phases in Dental Amalgam
}

\author{
LEONARD N.JOHNSON, * KAMAL ASGAR, and FLOYD A. PEYTON \\ Department of Dental Materials, School of Dentistry, University of Michigan, Ann Arbor, \\ Michigan 48104
}

An etch resistance phase was found in dental silver amalgam when the amalgam was examined metallographically. This phase was common to the silver alloy ingot as well as to its prepared amalgam. Qualitative electron microprobe technics were used to identify this phase. Quantitative electron microprobe analysis defined it as the ' $\eta^{\prime}$ phase of the copper-tin system or the intermetallic compound $\mathrm{Cu}_{6} \mathrm{Sn}_{5}$.

Many investigators have studied the reactions which occur in the formation of dental amalgam from the basic silver-tin-copper alloy and the phases which result. ${ }^{1-6}$ Equilibrium diagrams are not available for the silver-tin copper ternary system, so little is known about the unamalgamated alloy. Although the silver-tin, ${ }^{1,3,4,7,8}$ silver-mercury, ${ }^{1,3,4,7-11}$ and tin-mercury ${ }^{1,3,4,6-12}$ phases have been defined, the possible alloys with copper and their location have not been reported. The purpose of this investigation was first to locate the phase or phases that copper forms when it combines with the other constituents of the silver amalgam alloy and its respective amalgam and then identify the phases by use of electron microprobe technics.

In general, two different silver amalgam alloys are presently used in dentistry; one alloy does not contain zinc, and the other alloy has a zinc concentration not exceeding $2 \%$. Since the presence of zinc showed no effect on the analysis, only the "zincfree" alloy and amalgam will be considered.

This paper is based on a thesis submitted to the Horace H. Rackham School of Graduate Studies, University of Michigan, in partial fulfillment of the requirements for the $\mathrm{PhD}$ degree and was presented in part before the Dental Materials Group of the IADR in Miami, March 26, 1966. This investigation was supported by USPHS Training Grant No. 5T1 DE 13-08 from the National Institute of Dental Research, National Institutes of Health, Bethesda, Md.

Received for publication June 19, 1968.

* Present address: Faculty of Dentistry, University of Western Ontario, London, Ontario, Canada.

\section{Materials and Methods}

A silver amalgam alloy ingot $\dagger$ containing $70 \%$ silver, $26.2 \%$ tin and $3.8 \%$ copper was sectioned to an appropriate size for convenient handling and mounting. Small rectangular amalgam beams were also fabricated by mixing the aforementioned alloy, in a finely divided form, with an equal weight of mercury. The silver dental alloy and its respective amalgam were subjected to electron microprobe analyses. The qualitative results established that the two phases of interest were indeed of the copper-tin system. The phases were then examined by the probe quantitatively, and these results were used to define the stoichiometric relationships of the copper and tin in the phases. This method will be referred to as a "step" analysis. The phases thus identified were then correlated with the known phases shown in the copper-tin equilibrium diagram (Fig 1).

The procedure for polishing and etching of the specimens was the same as that described by Allan, Asgar, and Peyton. ${ }^{1}$ The silver-tin-copper amalgam alloy and its respective amalgam were embedded in mounting resin $\ddagger$ and the sample was shaped to fit the sample holder of the electron microprobe§ (three-sixteenth inch by one inch diameter). In addition to the amalgam and amalgam alloy samples, electrolytic silver, copper, reagent grade tin, and zinc were mounted as calibration standards for the step analysis. In subsequent analyses, it was necessary to fabricate two experimental alloys of copper and tin, which corresponded to the two intermetallic compounds indicated on the copper-tin equilibrium diagram (Fig $1)$, namely, $\varepsilon$ phase $\left(\mathrm{Cu}_{3} \mathrm{Sn}\right)$ and $\eta^{\prime}$ phase

$\uparrow$ Zinc-Free True Dentalloy, S. S. White Dental Mfg. Co., Philadelphia, Pa.

* Castolite, The Castolite Co., Woodstock, Ill.

$\$$ A.R.L. Model 21,000 No. 12, Applied Research Laboratory, Glendale, Calif. 


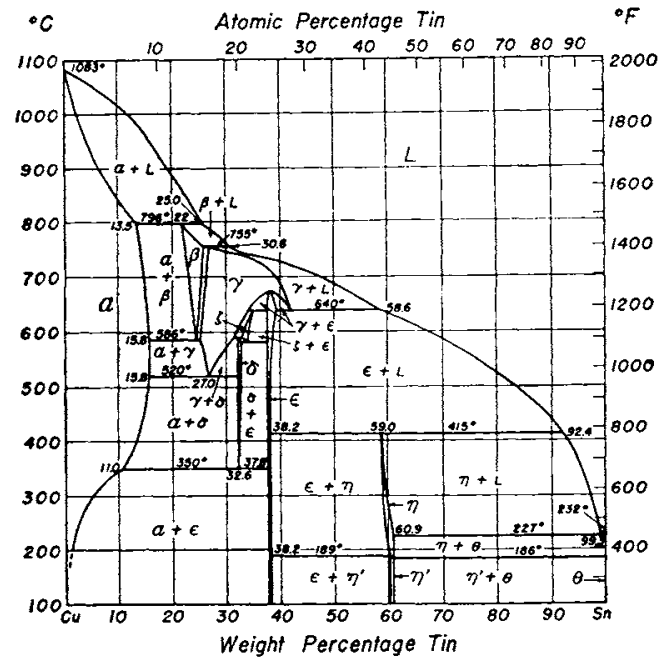

FIG 1.-Copper-tin equilibrium diagram.

$\left(\mathrm{Cu}_{6} \mathrm{Sn}_{5}\right)$. After the polish was attained, the samples were etched using the iodine etch technic described by Allan, Asgar, and Peyton. ${ }^{1}$ Because of the complex nature of this alloy and its respective amalgams, the aforementioned etchant was preferred because all the phases of the silver-tin system, silvermercury system, and tin-mercury system can be clearly delineated. Moreover, this etchant allows one to differentiate between the $\gamma$ (gamma) phase $\left(\mathrm{Sn}_{7} \mathrm{Hg} / \mathrm{Sn}_{8} \mathrm{Hg}\right)$ of the tinmercury system ( $\gamma_{2}$ of the amalgam system), which is easily lost during polishing, and voids that may occur in the amalgam.

(In the study of dental silver amalgam, three binary systems are of particular interest; namely, the silver-tin, silver-mercury, and tin-mercury. The $\gamma$ phase of each of the aforementioned binary equilibrium diagrams is of primary interest. Reference to simply the $\gamma$ phase of dental silver amalgam would lead to confusion. The convention used by metallurgists when referring to the respective binary equilibrium diagrams of dental silver amalgam, suggests that all silvermercury phases use a subscript number 1 , eg, $\beta_{1}, \gamma_{1}$, and so on and that all tin-mercury phases use a subscript number 2 , eg, $\gamma_{2}, \varepsilon_{2}$, and so on. If mercury is not included in the binary alloy, as in the silver-tin system, then no subscripts are used, and the phases are indicated simply as $\beta, \gamma$, etc. Therefore, the subscript number 1 is used for all phases of the silver-mercury system and the subscript number 2 is used for all phases of the tin-mercury system, and the subscripts are omitted when referring to the phases of the silver-tin system which suggests the absence of mercury.)

After polishing and etching, the amalgam alloys and their respective amalgated samples were subjected to metallographic analysis. During metallographic examination, two distinct phases not identified in previous works were observed. The areas of interest on the samples were marked with a diamond indenter to facilitate their relocation in the electron probe analysis. The amalgam alloys and their amalgams were repolished on the last two wheels to eliminate any possible interference effects due to the iodine etchant. Then, to increase electrical conductivity and thus prevent the buildup of an electrical charge during analysis, the edges of the specimens were painted with a silver "dope."

During qualitative analysis with the electron probe, the electron beam was focused on the area of interest. The spectrometers were automated so that the wavelengths of the primary $\mathrm{X}$ rays emitted from the specimen could be scanned and identified. The scanning interval included wavelengths of $2.75 \mathrm{~A}-4.75 \mathrm{~A}$. The data obtained by this method will be referred to as a "profile scan" and is similar in some respects to that described by Allan, Asgar, and Peyton. ${ }^{1}$

The emitted $X$ rays were focused with an ADP (ammonium dihydrogen phosphate) crystal and were detected by a proportional counter using P-10 (argon $+10 \%$ methane) as the detector gas. An input of 100 microamperes was used for all analysis. Twentyfive kilovolts was chosen as the operating voltage in order to minimize penetration of the electron beam into the sample. In the case of the profile analyses, a scanning rate of $0.1 \mathrm{~A} /$ minute with a chart speed of 1.5 inches/minute gave sufficient resolution of the various peaks.

The step analysis technic, used to determine the composition of the copper rich phases, required the use of the pure elements indicated from the profile analysis (silver, tin, copper, and zinc) as standards. The spectrometers were "peaked," using the recorder, by seeking the appropriately chosen wavelength with a spectrometer. Since the pure element can be considered as $100 \%$, the proportionally decreased deflection obtained during the analysis of the sample for that element indicates roughly 
the actual percentage present. The spectrometer was set to read $\mathrm{L}_{\beta 1}$ line of silver, $\mathrm{K}_{a_{1}}$ line of copper, and the $\mathrm{L}_{\beta 1}$ line of tin.

Corrections for enhancement, fluorescence, absorption, and atomic number were made according to Birks. ${ }^{13}$

\section{Results and Discussion}

Amalgam is particularly difficult to polish since it is composed of particles of relatively hard intermetallic compounds embedded in a softer matrix material. The polishing procedure can easily result in relief, particularly at or near grain boundaries, in which case erratic results can be expected from the electron microprobe analysis. Any departure from planarity of the alloy surface causes variations in the X-ray intensities to varying degrees. The current procedure proved to be satisfactory.

Careful metallographic scanning and examination with the metallograph resulted in the occasional observation of two phases or areas that did not respond to the iodine etchant. This observation was more pronounced in the amalgam alloy than in the amalgamated alloy. One area was blue-gray in color and "ameboid" in shape. The second area was white and more regular in shape. However, one must be careful to recognize the difference between the phase shadings and possible shadings created by relief in the sample surface. Phases of similar description were described by Allan, Asgar, and Peyton ${ }^{1}$ to consist of $\mathrm{Cu}$ and $\mathrm{Sn}$, and by Crowell ${ }^{2}$ to be $\mathrm{Cu}_{3} \mathrm{Sn}$. No quantitative analyses, however, were presented in either case.

Profile anAlysis.-Figure $2 A$ shows the two areas contained within the four microindentations. Spots numbered one to six were selected for profile analysis (Fig $2 A$ ). The profiles taken of the amalgam alloy ingot, assembled for comparison, are shown in Figure $2 B$. The profiles for spots no. one, no. three, and no. six, representing the matrix, were identical and could be superimposed; therefore, they were treated as one profile and labeled as spot no. one in Figure $2 B$. The matrix had a high silver content with lesser amounts of tin and was essentially void of copper. Spot no. two showed a decided increase in the tin content with an obvious increase in the copper content. Spot no. four represents an uncertain area, and the results can vary greatly depending

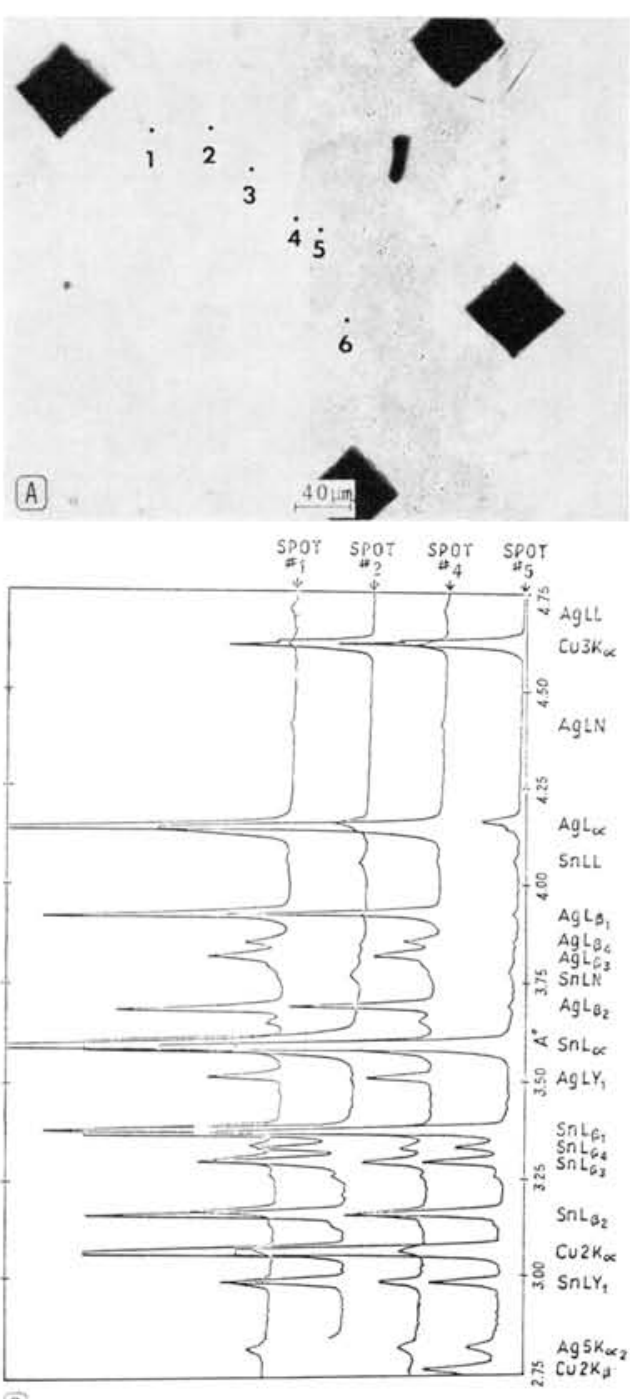

(B)

FIG 2,A.-Microstructure of ingot prepared for profile analysis. Spot no. one, matrix; spot no. two, white phase; spot no. three, matrix; spot no. four, boundary between blue-gray phase and matrix; spot no. five, blue-gray phase; spot no. six, matrix. $B$, Profile analysis of spots indicated in Figure $2 A$.

on how the electron beam saddles the phase boundary. Nevertheless, in the transition from spot no. one into spot no. five, the silver decreased and the tin and copper increased. Spot no. five was almost totally lacking in silver, but had a high copper content. The tin content of spot no. five, was much less than that of spot no. two. 

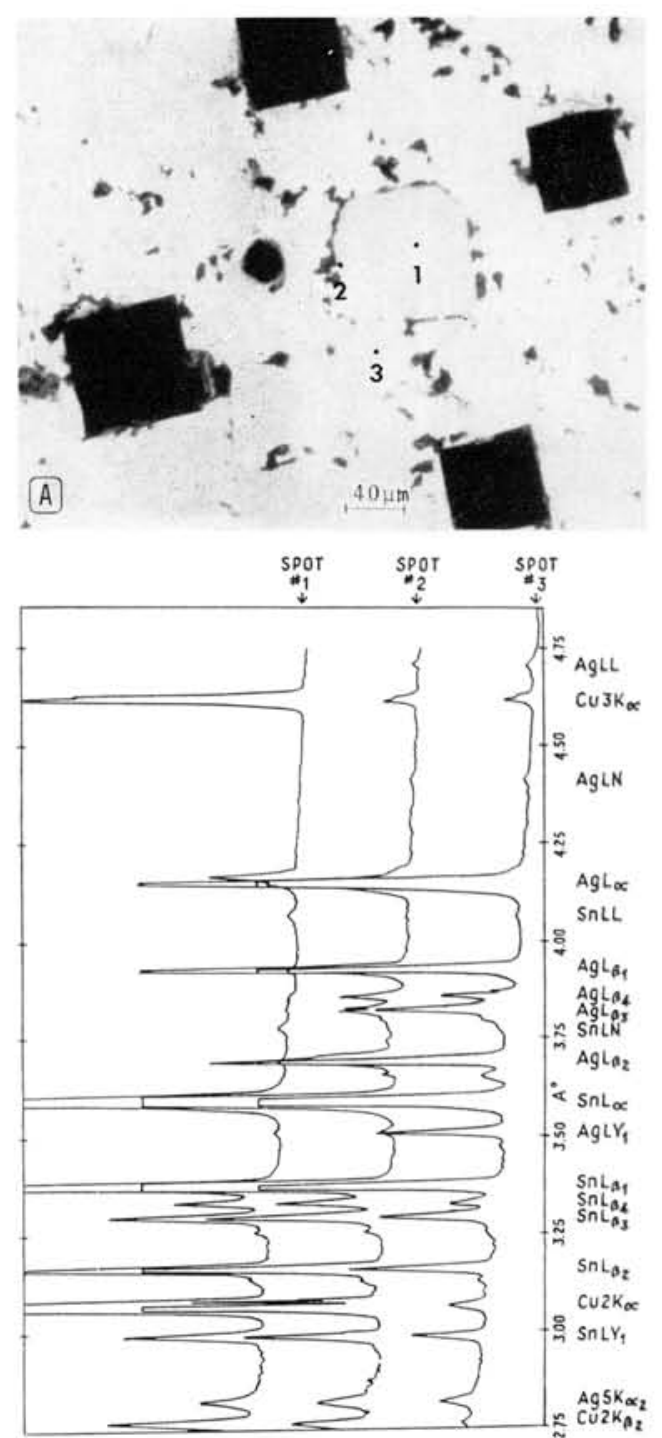

B

FIG 3,A.-Microstructure of amalgam prepared for profile analysis of the blue-gray area. Spot no. one, blue-gray phase; spot no. two, phase-matrix boundary; spot no. three, matrix. $B$, Profile analysis of spots indicated in Figure $3 A$.

Figure $3 A$ is a photomicrograph of an amalgam made from the amalgam alloy containing the blue-gray phase. The profile analysis of the three areas is shown graphically in Figure $3 B$. Spot no. one was essentially void of silver, but rich in copper and tin. Spot no. two was high in tin, had an increased silver content, but had essentially no copper. Spot no. three appeared to be high in silver with lesser amounts of tin and essentially no copper.

STEP ANALYSIS.-Figure $4 A$ shows a kidney-shaped blue-gray phase found in the amalgam. A path along the long axis of the phase was chosen for the step analysis. The corrected recorded data were plotted as atomic percentage vs the step interval in microns (Fig $4 B$ ). The graph is exceedingly simple because of the homogeneity of the phase. The copper content of the blue-gray phase ranged from 57 to 59 atomic percentage, the tin content ranged from 37 to 39 atomic percentage, and silver was of minor importance. The atomic ratio of copper to tin approximated $55 / 45$, corresponding to the $\eta^{\prime}\left(\mathrm{Cu}_{6} \mathrm{Sn}_{5}\right)$ intermetallic compound.

The ingot (Fig $5 A$ ) revealed a relatively large amount of the blue-gray phase,

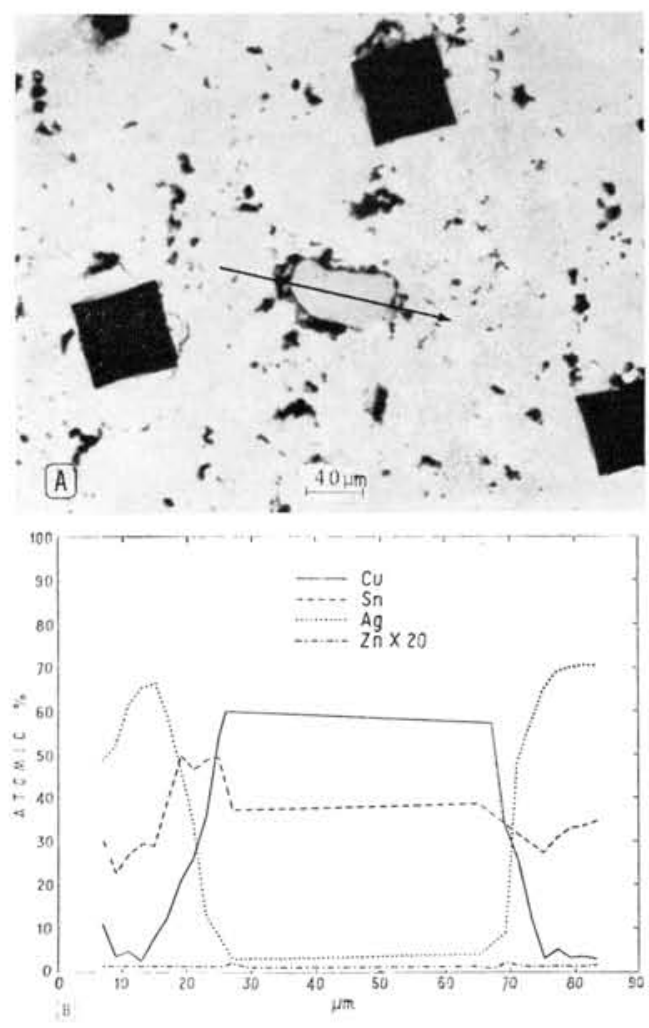

Fig 4,A.-Microstructure of amalgam prepared for step analysis. Arrow shows anticipated path of electron beam across blue-gray phase. $B$, Step analysis of path indicated in Figure $4 A$. 

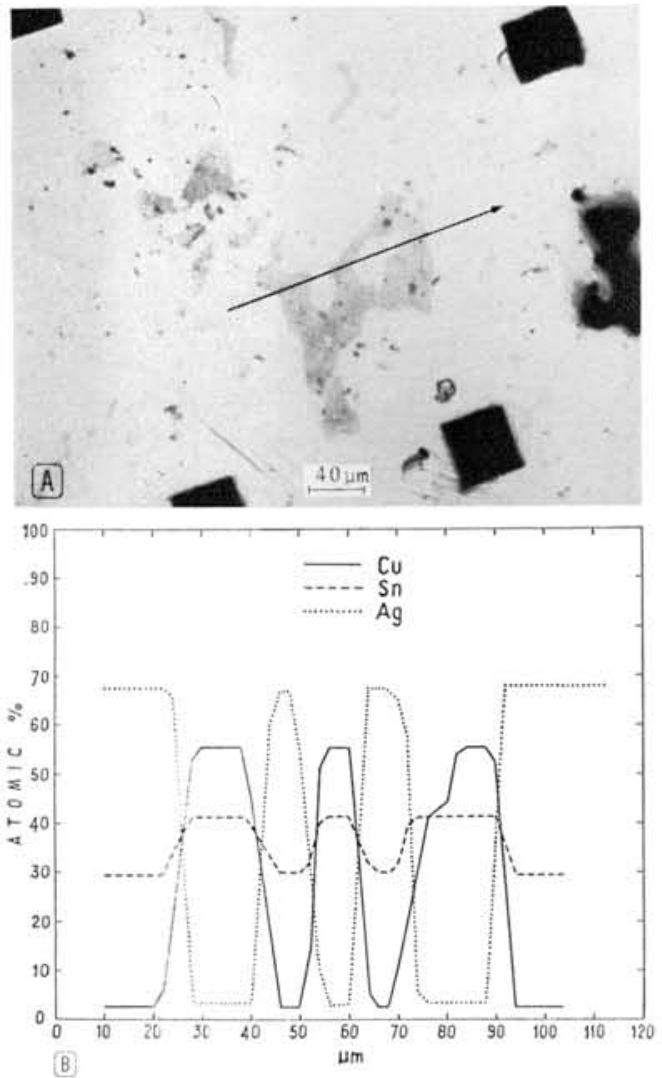

FIG 5,A.-Microstructure of ingot prepared for step analysis. Arrow shows anticipated path of the beam across a blue-gray phase. $B$, Step analysis of path indicated in Figure $5 A$.

bounded by the four microindentations. The desired scanning path started in the matrix and traversed a portion of the blue-gray phase, a "bay" with the same composition as the matrix, a small segment of the bluegray phase, an island of the same composition as the matrix, a small segment of the blue-gray phase, and finally ended in the matrix (order shown by arrow). Atomic percentage plotted against step intervals in micrometers is shown in Figure $5 B$.

The analysis revealed information similar to that of the preceding analysis. Whenever the electron beam was in the matrix, copper dropped to an insignificant amount and the silver rose to a very high level whereas tin fell about midway between the two. But when the electron beam was in the blue-gray phase, the silver dropped to an insignificant value and the copper rose sharply, followed by the usual smaller increase in tin. Again, the atomic ratio of the copper to tin was similar to that of previous analyses which approximated $55 / 45$ atomic percentage in the blue-gray phase.

Comparison of the atomic ratios of the copper to tin of the blue-gray phase and with the copper-tin equilibrium diagram (Fig 1), suggests that the blue-gray phase corresponds to the $\eta^{\prime}$ phase $\left(\mathrm{Cu}_{6} \mathrm{Sn}_{5}\right)$ of the copper-tin system. This is contrary to what has been reported in the literature and to what is usually accepted today. Crowell ${ }^{2}$ suggested that the copper would probably occur as the $\varepsilon$ phase $\left(\mathrm{Cu}_{3} \mathrm{Sn}\right)$ of the coppertin system. He also suggested that the $\left(\mathrm{Cu}_{3} \mathrm{Sn}\right)$ phase was analogous to the $\mathrm{Ag}_{3} \mathrm{Sn}$ phase and that copper and silver could replace each other in their respective compounds. However, Crowell did not positively identify the copper phase, nor did he present data to substantiate his reasoning.

Since present results were in disagreement with the literature, a comparison with experimental alloys representing the two intermetallic compounds of the copper-tin system [the $\eta^{\prime}$ phase $\left(\mathrm{Cu}_{6} \mathrm{Sn}_{5}\right)$ and the $\varepsilon$ phase $\left.\left(\mathrm{Cu}_{3} \mathrm{Sn}\right)\right]$ were made.

Figure 6 shows the copper-tin alloy of $\eta^{\prime}$ composition with its step analysis. The results were essentially the same as those obtained from the ingots and their respective amalgams. The initial analysis of the blue-gray phase indicated it to be the $\eta^{\prime}$ phase $\left(\mathrm{Cu}_{6} \mathrm{Sn}_{5}\right)$ of the copper-tin system. When the analysis proceeded to the white phase, an increase in tin content was observed with a corresponding decrease in copper content. The electron beam reentered the copper rich $\eta^{\prime}$ phase and emerged in the matrix which was essentially $100 \%$ tin (more appropriately, the copper-tin eutectic). These data indicated that the blue-gray area is the $\eta^{\prime}$ phase surrounded by a coppertin phase that is richer in tin to varying degrees depending on composition and equilibrium conditions.

Figure 7 shows the experimental coppertin alloy whose composition was approximately that of the $\varepsilon$ phase $\left(\mathrm{Cu}_{3} \mathrm{Sn}\right)$ of the copper-tin system with its step analysis. The composition and cooling rate were such that a small amount of the $\eta^{\prime}$ phase $\left(\mathrm{Cu}_{6} \mathrm{Sn}_{5}\right)$ was formed. This can be seen in the photomicrograph as the familiar blue-gray phase. Also, no copper-tin eutectic was formed. 


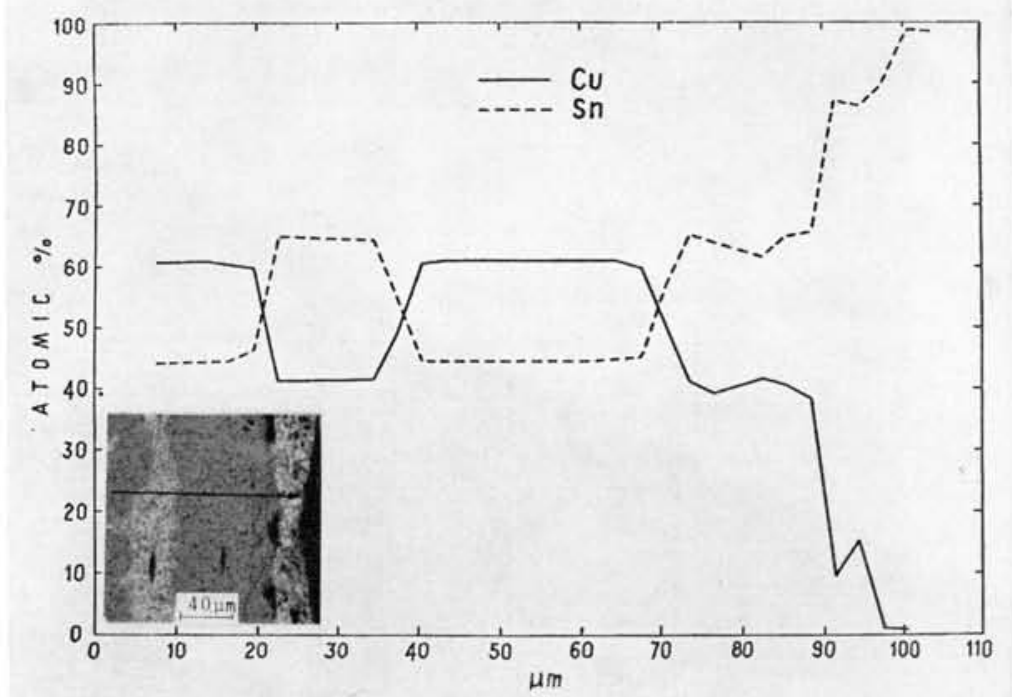

FIG 6.-Microstructure of an experimental $\eta^{\prime}$ copper-tin alloy, with step analysis whose path is shown by the arrow.

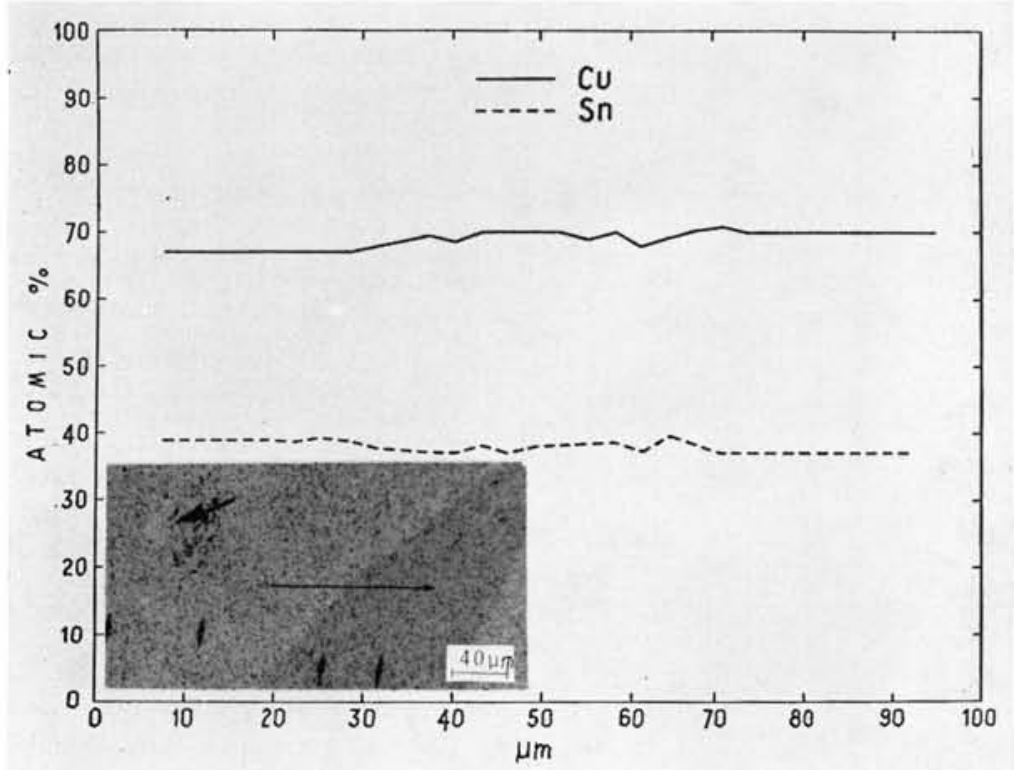

FIG 7.-Microstructure of an experimental $\varepsilon$ copper-tin alloy, with step analysis whose path is shown by the thin arrow.

This suggests that the composition of the experimental copper-tin alloy lay between the $\varepsilon$ phase $\left(\mathrm{Cu}_{3} \mathrm{Sn}\right)$ and the $\eta^{\prime}$ phase $\left(\mathrm{Cu}_{6} \mathrm{Sn}_{5}\right)$ of the copper-tin system, but close to the $\varepsilon$ phase. There also appeared to be two different shadings, one which was a lighter blue-gray and the other white. The path selected for the step analysis traversed the boundary between the white and the blue-gray areas.

The corrected recorded data were plotted as atomic percentage vs the step increments 
in micrometers. It is apparent from Figure 7 that the white area and the light blue-gray area had essentially the same composition. Apparently the shadings were because of relief. The atomic ratios of copper to tin were close to that of the $\varepsilon$ phase $\left(\mathrm{Cu}_{3} \mathrm{Sn}\right)$, and the slight departure from the stoichiometric ratio is explained on the basis of the actual composition and equilibrium conditions. More recent correction factors for fluorescence, absorption, and atomic number have been reported by Philibert-Duncumb ${ }^{14}$ and McKinley et al. ${ }^{15}$ The correction for Sn may amount to as much as $4.5 \%$ compared to 3\% using Birks' ${ }^{13}$ factors. This however, does not affect the results since the composition of the $\eta^{\prime}$ phase and $\varepsilon$ phase differ considerably.

\section{Conclusions}

Two particular phases were observed in the microstructure of the amalgam alloy and the amalgamated alloy. These two phases, one blue-gray and ameboid in shape, and the other white and regular in shape, were resistant to the described iodine etchant. These phases were analyzed qualitatively by adapting the electron microprobe to conduct profile analysis. Both phases contained copper and tin; the blue-gray phase had a greater percentage of copper than did the white phase and neither phase contained silver. The blue-gray phase was taken quantitatively analyzed by adapting the electron microprobe to use step analysis technics. Analyses of the phase occurring in amalgams and their respective ingots were compared with standards composed of copper and tin in the proportions to correspond to the $\varepsilon$ phase $\left(\mathrm{Cu}_{3} \mathrm{Sn}\right)$ and the $\eta^{\prime}$ phase $\left(\mathrm{Cu}_{6} \mathrm{Sn}_{5}\right)$ of the copper-tin system. The results showed the copper-tin phase in question was the $\eta^{\prime}$ phase $\left(\mathrm{Cu}_{6} \mathrm{Sn}_{5}\right)$ of the copper-tin system.

\section{References}

1. Allan, F.C.; Asgar, K.; and Ptyton, F.A.:
Microstructure of Dental Amalgam, J Dent Res 44:1002-1012, 1965.

2. Crowell, W.S.: The Metallography of Dental Amalgam Alloys, $J$ Dent Res 33: 592-595, 1954.

3. Frankel, C.B., and Fankuchen, I.: An Investigation of the Chemistry of Dental Amalgam by Roentgen Ray Diffraction, $J A D A$ 44:542-552, 1952.

4. GAYLER, M.L.V.: Dental Amalgams, J In.st Metals 60:407-424, 1937.

5. Ryge, G.; FaIRHURST, C.W.; and Fischer, C.H.: The Present Knowledge of the Mechanism of the Setting of Dental Amalgam, Int Dent J 11:181-195, 1961.

6. TAYLOR, D.F., and BURNS, C.L.: An Investigation of the Constitution of the Mercury-Tin System, $J$ Res National Bureau of Standards-A. Physics and Chemistry 67A:55-70, 1963.

7. GAYLER, M.L.V.: The Constitution of the Alloys of Silver, Tin, and Mercury, I Inst Metals 60:379-406, 1937.

8. Ryge, G.; MoffetT, J.C.; and Barkow, A.G.: Microstructural Observations and XRay Diffraction Studies of Silver-Tin Amalgams, $J$ Dent Res 32:152-167, 1953.

9. Murphy, A.J.: The Constitution of the Alloys of Silver and Tin, $J$ Inst Metals 35: 107-129, 1926.

10. Moffett, J.C.; RYGe, G.; and Barkow, A.G.: Phase Changes in Silver-Tin Amalgams, J Appl Phys 23:1188-1189, 1952.

11. WING, G.: Phase Identification in Dental Amalgam, Aust Dent J 11:105-113, 1966.

12. Fatrhurst, C.W., and Ryge, G.: X-Ray Diffraction Investigation of the $\mathrm{Sn}-\mathrm{Hg}$ Phase in Dental Amalgam, $A d v X$-Ray Analysi. 5:64-70, 1962.

13. BIRKS, L.S.: Electron Probe Microanalysis, New York and London: Interscience Publishers, 1963, pp ix-253.

14. Campbell, W.J.; Brown, J.D.; and THATCHER, J.W.: X-Ray Absorption and Emission, review, Anal Chem 38:416R439R, 1966.

15. MCKinleY, T.D.; HeINRICH, K.E.J.; and WITLAY, D.B.: The Electron Microprobe, New York: John Wiley \& Sons, Inc., 1966, pp xvi-1035. 